\title{
REFERENCES
}

Baumann, E. (1892). Hoppe-Seyl. Z. 16, 268. Blix, G. (1932). Hoppe-Seyl. Z. 210, 87.

Briggs, A. P. (1922). J. biol. Chem. 51, 451.

Faraday, M. (1857). Philos. Trans. 147, 145.

Garrod, A. E. \& Hurtley, W. H. (1905). J. Physiol. 33, 206.

James, T. H. (1939). J. Amer. chem. Soc. 61, 648.

Lieb, H. \& Lanyar, F. (1929). Hoppe-Seyl. Z. 181, 199.

Medes, G. (1932). Biochem. J. 26, 917.

Metz, E. (1927). Biochem. Z. 190, 261.

Metz, E. (1930). Hoppe-Seyl. Z. 193, 46.
Neuberger, A., Rimington, C. \& Wilson, J. M. (1947). Biochem. J. 41, 438.

Neuberger, A. \& Webster, T. A. (1947). Biochem. J. 41, 449.

Sealock, R. R. \& Silberstein, H. E. (1940). J. biol. Chem. 135, 251.

Snell, J. M. \& Weissberger, A. (1939). J. Amer. chem. Soc. 61, 450.

Voigt, H. \& Heumann, J. (1928). Z. anorg. Chem. 169, 140.

Wieland, H. (1910). Ber. dtsch. chem. Ges. 43, 710.

\section{Studies on Alcaptonuria}

\section{INVESTIGATIONS ON A CASE OF HUMAN ALCAPTONURIA}

\author{
By A. NEUBERGER, C. RIMINGTON AND J. M. G. WILSON, The National Institute for Medical \\ Research, London, N.W. 3, the Department of Chemical Pathology and the Medical Unit, \\ University College Hospital Medical School, London, W.C. 1
}

(Received 18 November 1946)

The great interest which biochemists have taken in alcaptonuria is largely due to the fact that this metabolic error may be expected to yield information on the normal metabolic pathway of aromatic aminoacids. Such an expectation is based on the assumption that the formation of homogentisic acid is a step in the normal oxidation of phenylalanine and tyrosine and that the defect of the alcaptonuric consists of an inability to break down further this intermediary metabolite. The evidence for this interpretation has been fully presented by Garrod (1923) and has been further strengthened by recent work on the experimental production of alcaptonuria in animals by dietary means. Thus in normal white rats the administration of very large doses of phenylalanine leads to excretion of small amounts of homogentisic acid (Papagẹorge \& Lewis, 1938; Butts, Dunn \& Hallman, 1938), whilst a diet deficient in methionine and cysteine (Glynn, Himsworth \& Neuberger, 1945) or diets practically free of protein (Neuberger \& Webster, 1947) produce a marked alcaptonuria even with a normal intake of aromatic amino-acids. It has also been shown that guinea-pigs excrete homogentisic and $p$-hydroxyphenylpyruvic acids if they are given a diet deficient in ascorbic acid but enriched by tyrosine (Sealock \& Silberstein, 1940; Sealock, Perkinson \& Basinski, 1941). It is reasonable to assume that these dietary deficiencies produce alcaptonuria by affecting the cellular concentration of an enzyme or other factor necessary for the normal metabolism of tyrosine and phenylalanine rather than by endowing the organism with a new type of metabolic reaction not normally found. It may therefore be inferred that the oxidation involving homogentisic acid represents at least one pathway of the intermediate metabolism of aromatic aminoacids, probably common to all mammals.

The question as to whether all the tyrosine and phenylalanine which is catabolized passes through the homogentisic acid stage has been discussed at great length, and the earlier literature on this point is fully reviewed by Garrod (1923) and by Neubauer (1928). More recent papers indicate that at least in some cases reduction of nitrogen intake produces a disproportionate decrease in homogentisic acid output (Katsch, 1918, 1920; Braid \& Hickmans, 1929; Reinwein, 1931; Sachs, 1931; Lorenz, 1937). On the other hand Lieb \& Lanyar (1930) found in one case that the ratio of homogentisic acid to nitrogen in the urine remained fairly constant, although protein intake was greatly reduced. A critical examination of existing data on the output of homogentisic acid in relation to the dietary intake of precursors is rendered difficult by several factors. Most workers did not keep either the composition or the total amount of their diet constant during the experiment; they were also handicapped by the fact that the tyrosine and phenylalanine content of the proteins given was not even approximately known at the time. A further difficulty arises from the lack of statistical analysis of the basic data. The output of homogentisic acid by the alcaptonuric is subject to considerable daily variations, independently of the changes in the diet. In an attempt to obtain a greater constancy Langstein \& Meyer (1903) proposed the use of the ratio of homogentisic acid to urinary nitrogen $(H: \mathrm{N})$ as a measure of the rate of conversion of tyrosine and phenylalanine to homogentisic acid. The $H: \mathrm{N}$ ratio is certainly very useful, if the total protein intake varies from day to 
day; but the question, as to whether the variation which still occurs on a constant nitrogen intake is closely related to changes of nitrogen excretion, has to our knowledge never been investigated. The need for a proper statistical analysis is also obvious in the interpretation of the many experiments in which potential intermediates were added to the diet of the alcaptonuric and their rate of conversion to homogentisic acid was deduced from the increase of the $H$ : N ratio. The significance of such a change will obviously depend on the variability of this ratio on a constant diet without a supplement.

\section{PLAN OF PRESENT INVESTIGATION}

Having access to a case of alcaptonuria, we proposed to ascertain first the degree of daily variation in homogentisic acid output on a diet constant in composition and amount and to investigate to what an extent the variations in the daily output of homogentisic acid and urinary nitrogen are correlated. Knowing the standard variation it was intended to assess more quantitatively than has been possible in the past, to what an extent added tyrosine, phenylalanine or other possible intermediates are converted into homogentisic acid.

In spite of the large amount of work which has been done on the 150-200 cases of alcaptonuria which are described in the literature, there are still some gaps in our knowledge of this condition. Thus, in the experimental alcaptonuria in guinea pigs (Sealock et al. 1941) and also in the disturbance of the metabolism of aromatic amino-acids which occurs in premature infants (Levine, Marples \& Gordon, 1941) a number of intermediate products of tyrosine metabolism such as keto and hydroxy acids are found in the urine. No systematic search for such substances has to our knowledge been made in cases of hereditary human alcaptonuria.

Another point about which there is a certain amount of confusion is the effect of ascorbic acid administration on human alcaptonuria (viz. Diaz, Mendoza \& Rodriguez, 1939; Monsonyi, 1939; Sealock, Galdston \& Steele, 1940; Leslie, 1943). We therefore decided to reinvestigate the effect of ascorbic acid on the output of homogentisic acid in our patient. It also appeared of interest to find out whether the alcaptonuric can deal in a normal manner with the extra ascorbic acid administered. This problem presents certain analytical difficulties, since phenol indo-2:6-dichlorophenol which is generally used for the estimation of ascorbic acid has an oxidation potential very close to that of homogentisic acid. We have therefore explored other methods for the estimation of ascorbic acid, applicable to alcaptonuric urines.

In rats alcaptonuria can be produced by giving a diet deficient in methionine and cysteine (Glynn et al. 1945) and it appeared possible, at least at the time when our investigations on human alcaptonuria were carried out, that this inborn error might be associated with a disturbance of sulphur metabolism. Such a suggestion appeared to be supported by the report of a single case of combined cystinuria and alcaptonuria (van Amstel, 1910). We proposed therefore to study the effect of the administration of extra cysteine and methionine to the alcaptonuric patient. It may be added, however, that later investigations (Neuberger \& Webster, 1947). have thrown considerable doubt on the supposition that the alcaptonuria observed by Glynn et al. (1945) was specifically caused by a deficiency of sulphur-containing amino-acids.

The researches of Wolkow \& Baumann (1891), Falta (1904), Langstein \& Meyer (1903) and especially those of Neubauer (1909) have established the fact that tyrosine and phenylalanine are the precursors of homogentisic acid and have also thrown much light on the intermediate steps involved in these transformations. Thus the observations that $p$-hydroxyphenylpyruvic acid gives rise to the excretion of extra homogentisic acid (Neubauer, 1909), whilst both $o$ - and $p$-hydroxyphenylacetic acids are inactive in this respect (Blum, 1908) lead to the conclusion that the introduction of the second hydroxyl group into the phenolic ring and the concomitant shift of the side chain precede the oxidation of the alanine or pyruvic acid to the acetic acid structure. But as Neubauer (1928) points out, it is still uncertain, whether the oxidation proceeds from $p$ hydroxyphenylpyruvic acid through 2:5-dihydroxyphenylpyruvic acid to homogentisic acid or whether 2:5-dihydroxyphenylalanine is the intermediate. Since this amino-acid, which has so far not been tested as a potential precursor of homogentisic acid, was available to us through a convenient synthesis (Neuberger, 1947b), we decided to investigate its metabolism in some detail.

In the normal dog homogentisic acid is oxidized to acetone and probably other ketone bodies in the liver, as shown by Embden, Salomon \& Schmidt (1906) in perfusion experiments. It is likely that in the normal man also, the liver is responsible for the further breakdown of homogentisic acid. We are, however, quite ignorant as to where this substance is formed or about the mechanism of its excretion by the kidney of the alcaptonuric. The concentration of homogentisic acid in the blood of alcaptonurics has been estimated in the past by a rather unspecific method which was based on the reduction of phosphomolybdic acid in alkaline solution (Katsch \& Metz, 1927; Lanyar \& Lieb, 1931). The values obtained by this method were of the order of about $3 \mathrm{mg} . / 100 \mathrm{ml}$. of plasma. On the other hand Abderhalden \& Falta (1903) claimed actually to have isolated this acid in the form of its lead salt from $300 \mathrm{ml}$. of blood taken from an alcaptonuric; the significance of this finding must, however, remain doubtful, since neither the yield, melting point, nor analysis of this lead salt are stated. It appeared desirable therefore to find out by more specific methods (Neuberger, 1947a) what the concentration of homogentisic acid in blood of the fasting alcaptonuric is, to compare the concentration in plasma and urine, and thus arrive at some definite conclusions as to transport and renal clearance of this intermediary metabolite.

Lastly we may consider the genetic basis of alcaptonuria. This aspect has been reviewed by Hogben, Worrall \& Zieve (1932) who have carried out a careful analysis of all the available data. These authors point out that the findings in the majority of cases are consistent with the hypothesis that this condition is determined by a single autosomal recessive gene substitution. There are, however, a few cases on record in which a dominant mode of transmission is suggested by the fact that alcaptonuria was present both in the parent and in the offspring. It appeared desirable therefore to test the urines of other members of the family for homogentisic acid. If our case belonged to the usual type of alcaptonuria, then both parents and probably other blood relations of our patient must be heterozygous with regard to the gene in question. Now it has been shown that 
many genes in man classed as recessive affect the phenotype of the heterozygous individual to some extent. The presence of minute amounts of homogentisic acid in the heterozygous parents might escape detection by the usual qualitative methods, but it was hoped that more sensitive techniques might reveal traces of the acid.

\section{General description of the case}

The patient, a girl of 6 years 11 months, was brought to the Diabetic Clinic, University College Hospital, where the presence of unusual reactions with Benedict's reagent and ferric chloride were confirmed.

The mother had noticed that the diapers were stained in early infancy, but she had never been perturbed over the matter and did not seek medical advice, until the patient was 3 years old, when she consulted a physician, because the child was overweight. No observation on the urine was apparently made at that time. The family history will be fully discussed in a later section of this paper. The patient is the only child of elderly parents, the father being 56 years and the mother approximately 45 . The weight is in gross excess of normal. Otherwise the personal history presents no unusual features.

On clinical examination the patient looked rather older than her 7 years. Her weight was $82 \mathrm{lb} .5 \mathrm{oz}$. whereas the expected weight for her age is $47 \mathrm{lb}$. The height was 50 in. compared with the expected height of 45 in. There was no abnormal pigmentation of the sclerotics and the cartilages of the ears and nose were of normal colour. Further systematic examination revealed nothing abnormal, save in the urine. The patient remained in hospital for about 6 weeks; during that time her weight remained quite constant. She was again readmitted at a later date for a period of 3 days. All the investigations recorded in this paper were carried out during these two periods.

\section{METHODS}

Estimation of homogentisic acid. The urine was collected over a $24 \mathrm{hr}$. period and stored in bottles containing $100 \mathrm{ml}$. of approximately $\mathrm{N}-\mathrm{HCl}$. Estimations for homogentisic acid were carried out in duplicate with the iodometric method; on most samples parallel determinations were also done by the reduction and Briggs's methods (Neuberger, 1947a). Agreement between the different methods was always within $5 \%$. For the calculation of homogentisic acid output the iodometric values only were used.

For the estimation of homogentisic acid in plasma, venous heparinized blood samples were centrifuged and deproteinized as quickly as possible. To $5 \mathrm{ml}$. of plasma were added either $2.5 \mathrm{ml}$. of a $5 \%$ (w/v) $\mathrm{HPO}_{3}$ solution (1st experiment) or $2.5 \mathrm{ml}$. of a $20 \%$ (w/v) trichloroacetic acid solution (2nd experiment). In the clear filtrates homogentisic acid was estimated both by the micro-iodometric and by the silver-reduction methods (Neuberger, 1947a). Results were also checked by the rather unspecific reduction of the Folin phenol reagent (Folin \& Ciocalteu, 1927) in alkaline solution using synthetic homogentisic acid as standard.

Determination of ascorbic acid in alcaptonuric urine. It was found, as expected, that homogentisic acid reduced phenol indo-2:6-dichlorophenol in a manner closely similar to that shown by ascorbic acid. However, the end point was not at all sharp, making an accurate determination impossible.

An attempt was made to determine ascorbic acid polarographically, utilizing the anodic wave in a manner similar to that employed in the analysis of fruit juices; interference by homogentisic acid was again encountered. The waves corresponding to the two substances overlapped almost completely under all conditions investigated. Pure homogentisic acid in aqueous solution gives a cathodic wave, but this is suppressed in urine.

The method finally selected for the determination of ascorbic acid in the alcaptonuric urine was based on the dinitrophenylhydrazine procedure of Roe \& Kuether (1943); in this method, which is fairly specific (Penney \& Zilva, 1945), ascorbic acid is converted into dehydroascorbic acid by shaking with charcoal in the presence of trichloroacetic acid. The method is not sufficiently sensitive for the accurate determination of the ascorbic acid normally present, but it is quite suitable for the estimation of excretion after a test dose.

Diet. The patient's diet was kept constant and all food returned to the kitchen was weighed so that a computation could be made of the daily intake of calories, protein, carbohydrate and fat. Detailed data of the composition of the diet are given in Table 1 which also includes an estimate of the daily intake of tyrosine and phenylalanine, the

\section{Table 1. Standard diet given to the patient}

(Total number of calories $=1850$.)

\begin{tabular}{l}
\multicolumn{1}{c}{ Food } \\
Milk \\
Breakfast cereal \\
Bread \\
Biscuit \\
Egg \\
Butter \\
Cake \\
Cheese \\
Cocoa \\
Meat \\
Potatoes \\
Cabbage
\end{tabular}

Total
Protein

$$
\text { (g.) }
$$$$
20
$$$$
2
$$$$
10
$$$$
\begin{array}{ll}
1 & 24 \\
5 & 75
\end{array}
$$$$
0 \cdot 5
$$$$
\text { 1.25 }
$$$$
1
$$$$
1
$$

$\mathbf{2}$

5

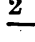

$(\mathrm{N} \times 6 \cdot 25)$ (g.)

30

75

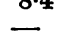

$\overline{15}$

15

2

$\overline{17 \cdot 5}$

4.8

$4 \cdot 8$
$176 \cdot 7$
Estimated sum of tyrosine and phenylalanine (g.) $2 \cdot 2$ $0 \cdot 18$ 0.95 0.09 0.30 $\overline{0.20}$ $0 \cdot 81$ $0 \cdot 20$ $\mathbf{0 . 6 7}$ 0.20 0.18 
calculations being based upon analyses given by Block \& Bolling (1945) or other recent publications. Where no figures were available a figure of $10 \%$ for the combined two aromatic amino-acids in the protein was assumed. It is realized that these estimates can be only rather rough. When all the diet was consumed it was estimated that the subject received in a day $177 \mathrm{~g}$. of carbohydrate, $60.4 \mathrm{~g}$. of protein, and $81.0 \mathrm{~g}$. of fat, making altogether 1848 calories. The tyrosine and phenylalanine intake was calculated to be $5.98 \mathrm{~g}$./day.

\section{RESULTS}

\section{Chemical investigations of the urine}

Identification of homogentisic acid. The urine gave the typical reactions with alkali, Benedict's reagent and $\mathrm{FeCl}_{3}$ and the homogentisic acid was identified by isolation.

Urine (1 1.) containing $10 \%(\mathrm{v} / \mathrm{v})$ of $\mathrm{N}-\mathrm{HCl}$ was extracted in a continuous extractor with peroxide-free ether for $18 \mathrm{hr}$. The ether solution was dried over $\mathrm{Na}_{2} \mathrm{SO}_{4}$, filtered and concentrated to about $50 \mathrm{ml}$. This ethereal solution was then extracted three times with $40 \mathrm{ml}$. portions of water and the homogentisic acid present in the combined aqueous solutions was precipitated by the addition of $40 \mathrm{~g}$. of lead acetate trihydrate dissolved in about $50 \mathrm{ml}$. of hot water. The precipitate was filtered off after standing at $0^{\circ}$ for $2 \mathrm{hr}$. The lead salt was twice recrystallized from water and dried in vacuo over $\mathrm{CaCl}_{2}$; it had m.p. 214-215 as reported by Wolkow \& Baumann (1891). The free acid was prepared by decomposing an aqueous suspension of the lead salt with $\mathrm{H}_{2} \mathrm{~S}$ and concentration of the solution in vacuo under nitrogen. The moist, crystalline residue was dissolved in ether, the ethereal solution dried and concentrated to low volume until crystallization started. Chloroform was then added and the crystalline material filtered off. It had m.p. 144-145 ; the m.p. was not depressed when the material was mixed with a specimen of synthetic homogentisic acid.

Search for other aromatic substances. The urine, after four extractions, each time with 12 vols. of ether, gave no reduction with Benedict's reagent, ammoniacal silver nitrate or Briggs's reagent, indicating the almost complete absence of reducing substances soluble in water and insoluble in ether. The ether solution was then extracted with water as described above; this extraction transferred about $99 \%$ of the homogentisic acid back into the aqueous phase. The ethereal solution was then extracted three times with a solution containing $1 \% \mathrm{NaHCO}_{3}$. The $\mathrm{NaHCO}_{3}$ solution was then tested for reducing properties; similar tests were carried out on the ethereal phase, after evaporating the ether and taking up the residue in water. Results with both solutions were entirely negative. It follows that the reducing properties found originally in the urine were confined, after the fractionation, to the solution containing the bulk of the homogentisic acid. A comparison of estimations by the Briggs, the iodometric and the very specific silver reduction methods indicated that homogentisic acid was the only reducing agent present in this solution. This assumption was also supported by the fact that the amount of recrystallized lead homogentisate recovered corresponded to a yield of $70 \%$ calculated on the basis of the titration data.

Homogentisic acid and 2:5-dl-dihydroxyphenylalanine give a yellow-orange precipitate with the Millon reagent; this precipitate is, however, so insoluble that these two substances show no colour in the tyrosine estimation according to Folin \& Ciocalteu (1927). Tyrosine, $p$-hydroxyphenylpyruvic and -lactic acids give colours of equal intensity relative to the respective molecular weights (Medes, 1932). Many samples of urine of the alcaptonuric patient were tested by this method with completely negative results. It was concluded that the presence of significant amounts of these substances, i.e. tyrosine and the two phenolic acids, can be excluded.

In another experiment urine was extracted with ether as described above and the ethereal solution extracted with $0 \cdot 1 \mathrm{~N} \cdot \mathrm{HCl}$ to remove homogentisic acid. The ethereal phase was then extracted with $1 \% \mathrm{NaHCO}_{3}$ and the aqueous extract tested for keto acids by the method of Penrose \& Quastel (1937). The result was negative. In a model experiment it could be shown that phenylpyruvic acid added to urine could be recovered to the extent of $90-95 \%$ by this method.

\section{The output of homogentisic acid under different conditions}

Intake and urinary output of nitrogen. The excretion of nitrogen and of homogentisic acid in the urine of the patient were estimated over a period of 32 days. The basal diet, as given in Table 1, was not consumed completely on some days, with the result that the average calculated daily $\mathrm{N}$ intake amounted to $9 \cdot 18$ instead of $9 \cdot 82 \mathrm{~g}$. The values for $\mathrm{N}$ intake cannot be considered very accurate, since these were based, not on actual estimations, but were calculated from the tables of McCance \& Widdowson (1940). The average daily $\mathrm{N}$ excretion in the urine during the experimental period was $9 \cdot 16 \mathrm{~g}$. with a standard deviation of $1 \cdot 14$. Since the faecal $N$ may be assumed to be about $5-10 \%$ of the total $\mathrm{N}$ output, it is calculated that the patient excreted on the average 9.6-10.0 g. N/day. It would thus appear that the patient was in a negative $N$ balance during the investigation, losing about $0.4-0.8 \mathrm{~g}$. $\mathrm{N} /$ day. We believe, however, that such a conclusion is unwarranted, especially, since the body weight did not change significantly during this period. It is more likely that the method of calculating $\mathbf{N}$ intake from food tables is not sufficiently accurate for our purpose, or that the patient consumed small additional quantities of protein without our knowledge. It is probable, therefore, that the calculated values both of total $\mathrm{N}$ intake and of potential homogentisic acid are too low by about 5-10\%.

Variations in the daily output of homogentisic acid and in the $H: \mathrm{N}$ ratio. Since the composition of the 
Table 2. Daily excretion of homogentisic acid and of $\mathrm{N}$ of the patient on the basal diet only

$\begin{array}{ccccc}\text { Date } & \begin{array}{c}\text { Vol. of urine } \\ (\text { ml. }\end{array} & \begin{array}{c}\text { Homogentisic } \\ \text { acid output } \\ \text { (g.) }\end{array} & \begin{array}{c}\text { Total N } \\ (\mathrm{g} .)\end{array} & \begin{array}{c}H: N \\ \text { ratio }\end{array} \\ \text {-26-27 Jan. } & 640 & 4 \cdot 87 & 9 \cdot 1 & 0 \cdot 535 \\ \text { 27-28 Jan. } & 885 & 4 \cdot 39 & 8 \cdot 9 & 0 \cdot 495 \\ \text { 28-29 Jan. } & 715 & 4 \cdot 65 & 9 \cdot 75 & 0 \cdot 477 \\ \text { 30-31 Jan. } & 1135 & 5 \cdot 14 & 9 \cdot 94 & 0 \cdot 517 \\ \text { 31 Jan.-1 Feb. } & 1175 & 5 \cdot 09 & 9 \cdot 26 & 0 \cdot 55 \\ \text { 1-2 Feb. } & 1015 & 3 \cdot 93 & 8 \cdot 74 & 0 \cdot 45 \\ \text { 4-5 Feb. } & 1040 & 5 \cdot 01 & 9 \cdot 98 & 0 \cdot 50 \\ \text { 5-6 Feb. } & 975 & 4 \cdot 19 & 8 \cdot 73 & 0 \cdot 48 \\ \text { 6-7 Feb. } & 750 & 3 \cdot 57 & 7 \cdot 02 & 0 \cdot 50 \\ \text { 10-11 Feb. } & 780 & 5 \cdot 12 & 9 \cdot 99 & 0 \cdot 512 \\ \text { 11-12 Feb. } & 1290 & 5 \cdot 23 & 11 \cdot 19 & 0 \cdot 468\end{array}$

diet did not vary at all from day to day and the quantity of food eaten remained nearly constant, it was expected that the output of homogentisic acid would vary very little. Table 2 which gives the relevant data for a representative 10-day period, shows that the fluctuations both of the daily output of homogentisic acid and of the $H: \mathrm{N}$ ratio were quite marked. The mean value of the output for the 32-day period was $4 \cdot 66 \mathrm{~g}$./day with a standard deviation of $0 \cdot 634$. The coefficients of variation for the excretion of $\mathrm{N}$ and of homogentisic acid were similar, $12.5 \%$ in the former and $13.6 \%$ in the latter.

These variations in the excretion of homogentisic acid are, however, associated with similar changes in daily $\mathrm{N}$ output. Thus the $H: \mathrm{N}$ ratio averaged 0.495 with a standard deviation of 0.05 ; the coefficient of variation was $10.4 \%$, definitely lower than the corresponding values for $H$ and $\mathrm{N}$ alone. Moreover, the correlation coefficient $R$ between daily output of $H$ and $\mathrm{N}$ was found to average $0 \cdot 793$, which is 4.4 times the standard error. This figure is statistically significant. It follows that even with a constant diet the $H$ : N ratio provides a more reliable basis for the interpretation of metabolic experiments than the absolute values of homogentisic acid output. But it is also clear that this correlation between $H$ and $\mathrm{N}$ is not complete and that part of the variability of homogentisic acid excretions is caused by factors not affecting output of $\mathrm{N}$.

The extent of the conversion into homogentisic acid of the tyrosine and phenylalanine present in the basal diet. It was calculated (Table 1) that the basal diet contained about $6 \mathrm{~g}$. of phenylalanine and tyrosine if fully consumed, which could give rise to a maximal daily excretion of $5 \cdot 8 \mathrm{~g}$. of homogentisic acid. When allowance is made for dietary items rejected on several days, this average figure is reduced to about $5.5 \mathrm{~g}$. This value is only approximate. As was pointed out above, the patient probably consumed about $10 \%$ more protein than our calculations indicate; moreover about $5-10 \%$ of the aromatic amino-acids ingested are likely to be excreted in the faeces. However, these two sources of error largely cancel each other and, if it is assumed that the ratio of potential homogentisic acid in the diet to total dietary $\mathrm{N}$ equals that ratio in the urine; then it follows that about $84 \%$ conversion has taken place. This follows from the fact that the calculated average dietary and urinary $\mathrm{N}$ are almost equal; the maximal potential homogentisic acid is therefore $5.5 \mathrm{~g}$. whilst the mean value for the daily excretion was $4 \cdot 66 \mathrm{~g}$. A very similar figure is obtained if the $H: \mathrm{N}$ ratios in the diet and in the urine are compared. The theoretical value for maximum conversion is 0.592 whilst the experimental figure is 0.495 ; from this calculation the rate of conversion is $83.6 \%$. This rather close agreement between the two calculations is rather illusory since both methods assume that the relative composition of the diet with respect to phenylalanine and tyrosine is known accurately. This is not the case; the analytical uncertainty is estimated to be about 5-10\%. It is concluded from this investigation that $80-100 \%$ of the tyrosine and phenylalanine present in the basal diet and catabolized by the patient are excreted as homogentisic acid in the urine; it is probable, that under the conditions used, the conversion is almost, but not quite, complete.

Effect of feeding additional $1(+)$-phenylalanine on the output of homogentisic acid. In order to gain further information as to the completeness of the conversion, $3 \mathrm{~g}$. of $l(+)$-phenylalanine were administered to the patient in addition to the basal diet, in three separate experiments. The amino-acid was given in a $1 \%$ solution at 10 a.m. and the urine was collected over the next $24 \mathrm{hr}$. It will be shown later that it can be safely assumed that the extra homogentisic acid is excreted in the first 6-8 hr. The results (Table 3 ) indicate clearly that the ingestion of the extra phenylalanine produced an increase, both in the output of homogentisic acid and in the $H: \mathrm{N}$ ratio. The values of the daily homogentisic acid output found in the three experiments are between 7.0 and $7 \cdot 4 \mathrm{~g}$; ; they differ from the mean of the control series by more than three times the standard deviation. The $H: \mathrm{N}$ ratios are even more conclusive; they differ from the mean value on the basal diet alone by more than five times the standard deviation. There is therefore no doubt that feeding phenylalanine leads to an increased excretion of homogentisic acid by the alcaptonuric. But these three experiments do not allow us to arrive at a 
definite conclusion as to what proportion of the amino-acid is converted into homogentisic acid. The calculated values in Table 3 were obtained by first

Table 3. Effect of the addition of $1(+)$-phenylalanine to the basal diet on the daily excretion of homogentisic acid

(The patient was given $3 \mathrm{~g}$. of the amino-acid in addition to the basal diet; this could give rise to a maximal additional excretion of $3.03 \mathrm{~g}$. of homogentisic acid.)

$\begin{array}{lccc} & \text { Test no. } 1 & \text { Test no. } 2 & \text { Test no. 3 } \\ \text { Total homogentisic acid } & 7 \cdot 17 & 7 \cdot 40 & 7.02 \\ \text { excreted (g./day) } & & & \\ \text { Total daily N (g.) } & 9 \cdot 39 & 9 \cdot 35 & 9 \cdot 15 \\ \text { H : N ratio } & 0 \cdot 764 & 0 \cdot 791 & 0 \cdot 767 \\ \text { Extra homogentisic acid (g.) } & \mathbf{2 \cdot 6} & \mathbf{2 \cdot 8 5} & \mathbf{2 \cdot 5 7} \\ \text { \% Conversion } & \mathbf{8 5} & \mathbf{9 4} & \mathbf{8 4} \cdot 8\end{array}$

correcting the total urinary $\mathrm{N}$ for the $\mathrm{N}$ derived from the extra phenylalanine. That fraction of the homogentisic acid due to the aromatic amino-acids contained in the basal diet was then calculated by multiplying the corrected $\mathrm{N}$ figure by $0 \cdot 495$. The difference between the total homogentisic acid and the calculated value of the fraction derived from the basal diet was ascribed to the extra phenylalanine fed. The mean value for this extra homogentisic acid in the three experiments was $2.67 \mathrm{~g}$., the standard error of the mean being 0.088 ; complete con- version would require $3.03 \mathrm{~g}$. The fiducial limits of error for $p=0.95$ are 2.29 and 3.055 . The results are thus consistent with any hypothesis which requires a conversion of between $75-100 \%$.

Effect of the administration of ascorbic acid on the output of homogentisic acid. The output of homogentisic acid and the $H: \mathrm{N}$ ratio did not change significantly, when the patient received $1 \mathrm{~g}$. of ascorbic acid/day for two consecutive days (Table 4). It also appears that the proportion of ascorbic acid excreted in the urine indicates that the alcaptonuric responds in a normal manner to the large dose of the vitamin administered.

Effect of the administration of cysteine and methionine on the output of homogentisic acid. Neither the ingestion of fairly large doses of methionine nor of cysteine alter significantly the homogentisic acid output or the $H: \mathrm{N}$ ratio (Table 5). In one experiment this ratio dropped considerably on the day after cysteine had been administered; but this observation could not be repeated and it seems unlikely that this decrease was caused by the administration of the amino-acid.

\section{Renal clearance of homogentisic acid}

Two experiments were carried out in which $3 \mathrm{~g}$. of $l(+)$-phenylalanine were administered to the patient by mouth and the concentration of homogentisic

Table 4. Excretion of homogentisic acid and ascorbic acid on administration of ascorbic acid on two consecutive days

\begin{tabular}{|c|c|c|c|c|c|c|}
\hline Date & Time & $\begin{array}{c}\text { Dose of } \\
\text { ascorbic acid } \\
\text { (mg.) }\end{array}$ & $\begin{array}{c}\text { Vol. of } \\
\text { urine } \\
\text { (ml.) }\end{array}$ & $\begin{array}{c}\text { Homogentisic } \\
\text { acid excreted } \\
\text { (mg./24 hr.) } \\
\text { (10 a.m.-10 p.m.) }\end{array}$ & $\begin{array}{l}H: \mathrm{N} \\
\text { ratio }\end{array}$ & $\begin{array}{c}\text { Ascorbic } \\
\text { acid excreted } \\
\text { (mg./24 hr.) } \\
(10 \text { a.m. }-10 \text { p.m. })\end{array}$ \\
\hline 2-3 Feb. & $\begin{aligned} 2 & \text { p.m. } \\
6 & \text { p.m. } \\
10 & \text { p.m. } \\
2 & \text { a.m. }\end{aligned}$ & $\begin{array}{l}250 \\
250 \\
250 \\
250\end{array}$ & 975 & $4 \cdot 20$ & $0 \cdot 477$ & $224 \cdot 3$ \\
\hline 3-4 Feb. & $\begin{aligned} 2 & \text { p.m. } \\
6 & \text { p.m. } \\
10 & \text { p.m. } \\
2 & \text { a.m. }\end{aligned}$ & $\begin{array}{l}250 \\
250 \\
250 \\
250\end{array}$ & 1000 & $4 \cdot 35$ & 0.579 & $581 \cdot 0$ \\
\hline 4-5 Feb. & - & Nil & 1140 & $5 \cdot 01$ & 0.50 & 68.4 \\
\hline 5-6 Feb. & - & Nil & 1060 & $4 \cdot 19$ & 0.48 & $4 \cdot 2$ \\
\hline
\end{tabular}

Table 5. The effect of the administration of cysteine and methionine on the excretion of homogentisic acid

\begin{tabular}{|c|c|c|c|c|c|}
\hline Date & Supplement & $\begin{array}{l}\text { Urine } \\
\text { vol. } \\
\text { (ml.) }\end{array}$ & $\begin{array}{l}\text { Homogentisic } \\
\text { acid excreted } \\
\quad \text { (g.) }\end{array}$ & $\underset{\text { (g.) }}{\text { Urinary } N}$ & $\begin{array}{l}H: \mathrm{N} \\
\text { ratio }\end{array}$ \\
\hline $\begin{array}{l}\text { 2-3 Feb. } \\
\text { 3-4 Feb. }\end{array}$ & $\begin{array}{l}6 \cdot 5 \text { g. l-Cysteine } \mathrm{HCl} \\
\text { Do. }\end{array}$ & $\begin{array}{r}940 \\
1200\end{array}$ & $\begin{array}{l}3 \cdot 62 \\
4 \cdot 99\end{array}$ & $\begin{array}{l}7 \cdot 59 \\
9 \cdot 23\end{array}$ & $\begin{array}{l}0.477 \\
0.532\end{array}$ \\
\hline 4-5 Feb. & Nil & 1025 & $3 \cdot 10$ & 7.99 & $\begin{array}{l}0.388 \\
0.388\end{array}$ \\
\hline 14-15 Feb. & Nil & 880 & 4.32 & $\mathbf{9 \cdot 4 0}$ & 0.459 \\
\hline 15-16 Feb. & 6 g. $l$-Cysteine $\mathrm{HCl}$ & 1610 & $5 \cdot 31$ & $11 \cdot 01$ & 0.483 \\
\hline 16-17 Feb. & Do. & 1025 & $5: 56$ & $10 \cdot 06$ & 0.550 \\
\hline 17-18 Feb. & Nil & 1200 & $5 \cdot 76$ & $10: 56$ & 0.545 \\
\hline 20-21 Feb. & $8 \mathrm{~g} . d l$-Methionine & 1590 & $5 \cdot 01$ & $10 \cdot 70$ & $0 \cdot 467$ \\
\hline 21-22 Feb. & Do. & 1300 & $4 \cdot 26$. & $9 \cdot 72$ & 0.438 \\
\hline 22-23 Feb. & Do. & 1135 & $5 \cdot 34$ & $10 \cdot 40$ & 0.513 \\
\hline
\end{tabular}


acid was measured at suitable intervals in plasma and urine. In the first test about 1.5-2 pints of liquid in the form of lemonade were given in the first few hours after the administration of the aminoacid, whilst in the second test no additional water was supplied. however, that homogentisic acid added to blood and incubated for a few hours at $37^{\circ}$, can be recovered by the methods used, to the extent of $70-75 \%$, renders this assumption unlikely.

Renal clearance volume. If it is assumed that the reduction observed in these plasma extracts is due

Table 6. Concentrations of homogentisic acid in plasma and urine after the administration of $3 \mathrm{~g}$. of $1(+)$-phenylalanine by mouth

(In the first test the amino-acid was given at 12 noon and in the second at 10 a.m.)

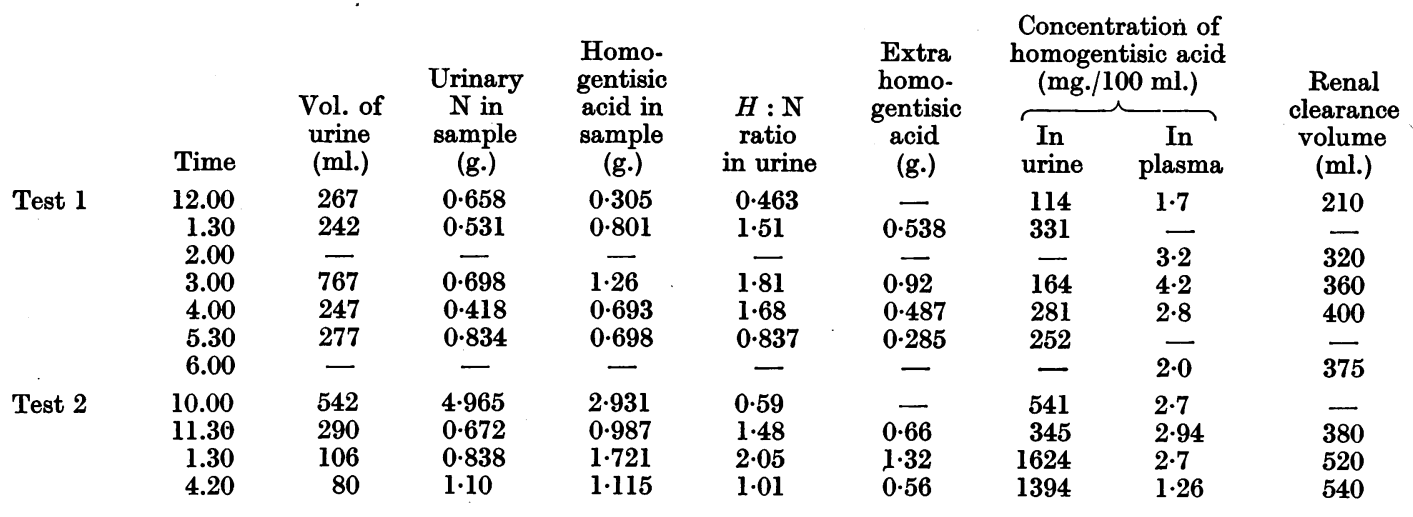

Rate of excretion of homogentisic acid in the urine. Table 6 shows that in both tests the $H: N$ ratio rose abruptly $1.5 \mathrm{hr}$. after phenylalanine was fed, reached a maximum after about $3-4 \mathrm{hr}$. and then again decreased. The extra homogentisic acid due to the phenylalanine fed was calculated on the assumption that the normal $H: \mathrm{N}$ ratio was 0.50 . In the first test the large amount of water given produced a diuresis, leading to low concentration of homogentisic acid in the urine; the extra homogentisic acid was almost all excreted in $4 \mathrm{hr}$. In the second test there was no diuresis, the urine was very concentrated and the excretion of homogentisic acid was apparently more delayed. About $80-85 \%$ of the dose administered appeared as homogentisic acid in the urine in the $6 \mathrm{hr}$. period following the administration of phenylalanine.

The concentration of homogentisic acid in plasma. The fasting level of homogentisic acid in the plasma was about $3 \mathrm{mg}$. $/ 100 \mathrm{ml}$.; the plasma concentration did not rise markedly after administration of phenylalanine. These concentrations are so low as to be near the lower limits of the applicability of the method, moreover, as was pointed out above, minute amounts of reducing substances reacting like homogentisic acid are present even in plasma extracts obtained from non-alcaptonuric patients and the plasma homogentisic acid values reported here can therefore not be considered as very accurate. The possibility that homogentisic acid is bound to plasma proteins and is not liberated by treatment with acid in the cold has been considered. The fact,

to homogentisic acid, renal clearance volumes can be calculated (Table 6). It can be seen that the values obtained are reasonably constant, varying between 400 and $500 \mathrm{ml}$. A substance which is filtered by glomeruli and not at all reabsorbed may be expected to show a clearance volume of about $70-80 \mathrm{ml}$. or at the most $100 \mathrm{ml}$. in our patient. It follows therefore, that if homogentisic acid is not elaborated in the kidney, but transported there by the blood, glomerular filtration alone cannot account for its rate of excretion. We have to assume that the acid, or at least most of it, is actively secreted by the tubuli.

\section{The conversion of 2:5-d1-dihydroxyphenylalanine to homogentisic acid}

Altogether three experiments have been carried out to test the possibility whether 2:5-dihydroxyphenylalanine is an intermediate in the formation of homogentisic acid by the alcaptonuric. In the first test, a total of $3.5 \mathrm{~g}$. of the racemic compound was given in four equal doses at $4 \mathrm{hr}$. intervals beginning at 10.a.m. The urinary excretion of $\mathrm{N}$ for the $24 \mathrm{hr}$. period was $9 \cdot 33 \mathrm{~g}$. and that of homogentisic acid $5 \cdot 6 \mathrm{~g}$.: the $H: \mathrm{N}$ ratio was therefore $0 \cdot 606$, i.e. higher than the mean of the control period by exactly twice the standard deviation. On the following day the $H: \mathrm{N}$ ratio had again dropped to 0.53 . In the second experiment $4 \mathrm{~g}$. of the amino-acid was given, also in divided doses; the $H$ : $\mathrm{N}$ ratio for the $24 \mathrm{hr}$. period was 0.59 , whilst on the following day it was still $\mathbf{0 \cdot 6 6}$. These results suggested, but did not conclusively prove, that an increase of homogentisic acid excretion had been produced by feeding 2:5-dihydroxyphenylalanine. The observed increases in the $H: \mathrm{N}$ ratio 
were on the borderline of statistical significance. Examination of the urine suggested that part of the amino-acid was excreted in the urine. Thus the urine after exhaustive ether extraction at $\mathrm{pH} 1.5$ exhibited strong reducing properties and turned dark on addition of alkali. The concentration of the amino-acid was estimated by making use of the fact that 2:5-dihydroxyphenylalanine reduces Folin's phenol reagent about $2 \cdot 2$ times as strongly as tyrosine on a molecular basis. The colour produced with the ether-extracted urine on the days preceding the test was fairly constant and was equivalent to about $0.5 \mathrm{~g}$. of tyrosine. On the day the amino-acid was fed and also on the following day, the value increased to 1.7 and $1.0 \mathrm{~g}$. respectively (in terms of tyrosine), to return again to the value of $0.6 \mathrm{~g}$. on the third day. Similar results were obtained in the second experiment. It is likely that the ether-insoluble reducing substance which is excreted is the $d$-form of the amino-acid and it appears that about $40 \%$ of the whole dose given is excreted unchanged.

In view of these findings it was felt that a more decisive result could be obtained by giving the whole of the amino-acid in one dose and estimating homogentisic acid and $\mathbf{N}$ content of the urine at short intervals afterwards. The results of this test (Table 7) show that a rise of the $H: \mathrm{N}$ ratio to a value of $1 \cdot 2$ was observed on feeding 2:5-dl-dihydroxyphenylalanine. It is therefore certain that this amino-acid can be converted to homogentisic acid in the same i.e. 35 or $70 \%$ respectively of the theoretical value. It is likely that this value would have been slightly greater if the collection of urine had been continued beyond the $6.5 \mathrm{hr}$. period.

\section{Family history of patient and examination of the urines of relatives}

There was no proven consanguinity between the parents, though the maiden name of the mother was the same as the name of the father. The parents, three aunts and an uncle were asked whether they recalled any history in their families of the passage of dark urine, arthritis, bluish staining of the cartilages or stone in the kidney. The replies were all completely negative.

Samples of morning urine of the parents and of 7 other relatives of the patient were examined for homogentisic acid by a slight modification of the silver-reduction method: $10 \mathrm{ml}$., instead of $2.5 \mathrm{ml}$., of acidified urine were extracted with altogether $480 \mathrm{ml}$. of ether, the ethereal solutions were concentrated to $5 \mathrm{ml}$. and the final aqueous extracts made up to $20 \mathrm{ml}$; $5 \mathrm{ml}$. of this solution, which were equivalent to $2.5 \mathrm{ml}$. of urine, were used for the estimation. An amount of homogentisic acid of 3-4 $\mu \mathrm{g} . / \mathrm{ml}$. of urine would just give a positive reading. The results, with one exception, were all negative and it was concluded that if any homogentisic acid was excreted by these subjects, it amounted to less than $5 \mathrm{mg}$. a day.

However, the urine of one cousin of the patient's mother gave distinctly positive reactions for homogentisic acid; one

\section{Table 7. The conversion of 2:5-dihydroxyphenylalanine to homogentisic acid}

(The patient received $3 \mathrm{~g}$. of $d l$-2:5-dihydroxyphenylalanine hydrate at 10 a.m. and urine samples were obtained later in the day at the times stated.)

\begin{tabular}{|c|c|c|}
\hline Time & $\begin{array}{l}\text { Vol. of } \\
\text { urine } \\
\text { (ml.) }\end{array}$ & $\begin{array}{l}\text { Total amount of } \\
\text { homogentisic } \\
\text { acid in sample } \\
\text { (g.) }\end{array}$ \\
\hline 10.00 & 130 & 0.515 \\
\hline 11.30 & 445 & 0.326 \\
\hline 1.00 & 85 & 0.462 \\
\hline 2.30 & 50 & 0.496 \\
\hline 4.30 & 145 & 0.609 \\
\hline
\end{tabular}

Total N
in sample
(g.)
0.918
0.554
0.378
$0 \cdot 409$
0.661

sample containing $280 \mathrm{ml}$. of urine gave a value of $33 \mathrm{mg}$. by the iodometric method and a value of $31 \mathrm{mg}$. by the silver-reduction method. The output of this reducing substance increased four to fivefold in the first $4 \mathrm{hr}$. after the ingestion of $3 \mathrm{~g}$. of $l(+)$-phenylalanine, to return to a lower value again after $5 \mathrm{hr}$. An attempt was made to isolate this material; $1150 \mathrm{ml}$. of acidified urine containing $550 \mathrm{mg}$. of this substance (in terms of homogentisic acid) were extracted with ether in a continuous extractor for $36 \mathrm{hr}$. and the ether extract was then concentrated to low volume. It was not possible to isolate either homogentisic acid or its very characteristic lead salt. Since homogentisic acid in similar concentrations can easily be isolated from urine with the technique employed, it seemed unlikely that the reducing substance in this urine was homogentisic acid. This conclusion was strongly supported by experiments carried out by Dr C. E. Dent in which partition chromatography was employed and the reaction with silver nitrate and ammonia was used to locate the different bands. Homogentisic acid gave an $R_{F}$ value of 0.55 (both in urine and in 
water), gentisic acid a value of 0.39 and the unknown substance a value of $\mathbf{0} \cdot 44$. Addition of homogentisic acid to this urine produced two distinct bands, whilst with gentisic acid, slight overlapping was observed. Dr Dent concluded that the unknown substance was neither gentisic nor homogentisic acid. The subject had not been taking drugs containing salicylic acid in the weeks immediately before this investigation was carried out, but was in the habit of taking aspirin and had done so for some months previously.

\section{DISCUSSION}

Chemical examination of the urine of the patient has revealed the absence of any substances other than homogentisic acid, likely to arise from the metabolism of tyrosine and phenylalanine. Human congenital alcaptonuria differs in this respect from the metabolic disturbance in aromatic amino-acid metabolism occurring in premature infants and also from the experimental alcaptonuria in guinea-pigs, both of which are caused by a dietary deficiency of vitamin C. It is most unlikely that human congential alcaptonuria is caused by, or associated with, an abnormality in the metabolism of ascorbic acid. In our patient at least, administration of large doses of ascorbic acid had no detectable influence on homogentisic acid output, nor was there any evidence of any inability to utilize this vitamin.

\section{Degree of conversion of phenylalanine and tyrosine into homogentisic acid}

As to the quantitative conversion of phenylalanine and tyrosine to homogentisic acid, our investigations have not produced an absolutely conclusive result. It has been shown that the excretion of homogentisic acid varies considerably from day to day, even on a diet kept almost constant. Statistical methods have therefore to be used, if the mean daily output and its variability are to be assessed. It would follow, in the light of the results reported here, that many of the observations recorded in the literature on the conversion of aromatic substances to homogentisic acid, are open to serious criticism. The main difficulty which is met in the quantitative interpretation of the data, is the uncertainty concerning the amino-acid composition of the proteins of the diet. However, it is believed that the intake of phenylalanine and tyrosine has not been overestimated, but rather the reverse, and we consider it very probable that, with the mixed diet used in this investigation, only about $80-85 \%$ of the total amount of the two aromatic amino-acids is converted by the alcaptonuric into homogentisic acid. Most of the $H$ : N ratios found by other workers vary between 0.40 and $0 \cdot 48$, with diets similar to ours, and it is likely that a conversion rate of $70-90 \%$ is usual with most alcaptonurics.

The tests in which extra phenylalanine was given, were again not quite decisive; as in order to obtain statistically conclusive results, the number of such tests would have had to be larger, but they also point to a conversion rate of about $80 \%$. It would be useless to discuss in detail all the many observations carried out on the conversion of extra phenylalanine and tyrosine into homogentisic acid, reported in the literature. It may be said, however, that all workers agree that with $l$-phenylalanine and $l$-tyrosine the conversion is either complete or nearly complete when small doses are given (Falta, 1904; Papageorge, Fröhlich \& Lewis, 1938). With bigger doses, such as $15 \mathrm{~g}$., the conversion is incomplete; this was already shown by Mittelbach (1901). It follows therefore that in the alcaptonuric the oxidation to homogentisic acid represents, under conditions of a mixed diet, the main, but most probably not the only catabolic pathway of the two aminoacids, tyrosine and phenylalanine, and the same probably applies to the normal individual.

Such a conclusion that other pathways exist, but are quantitatively of minor importance, is supported by all the other information we possess on the metabolism of aromatic amino-acids. Thus the conversion of phenylalanine to tyrosine which was first suggested by Embden \& Baldes (1913) from perfusion experiments and later conclusively demonstrated by Moss \& Schoenheimer (1940), using the isotope technique, is probably the main pathway of phenylalanine catabolism in mammals, but an alternative degradation, not leading through tyrosine, is by no means excluded.

As for tyrosine itself, we may assume, that the major part of this amino-acid is further oxidized in the para position to the original hydroxyl group. The main evidence for this supposition is obtained from the experiments discussed above, in which alcaptonuria was produced in laboratory animals by dietary means, and also from the work on congenital human alcaptonuria. There must, however, be other pathways. Thus the fact that neither adrenaline nor dopa are dietary essentials, strongly suggests that these substances are formed in the body from tyrosine. In the case of dopa, such a reaction has been clearly demonstrated by Medes (1932) although the claim that this oxidation is reversible cannot as yet be accepted. It follows that, apart from the paraoxidation, the body can introduce a second hydroxyl group into the position ortho to the phenolic group of tyrosine. It seems, however, that the capacity of the organism to effect this type of oxidation and to deal further with 3:4-dihydroxyphenylalanine is limited. Thus Guggenheim (1913), who ingested 2.5g. of this amino-acid himself, experienced toxic symptoms, and found that his urine gave positive catechol reactions. Ingestion of tyrosine even on a larger scale would not produce untoward subjective effects, nor would it lead to the excretion of catechol-like substances in the urine. Medes (1932) 
also found that, when dopa was fed to her case of tyrosinosis, some of the amino-acid was recovered from the urine, and Fromherz \& Hermanns (1914) reported that dopa was incompletely metabolized by the rabbit and not converted into homogentisic acid by the alcaptonuric. All these observations are compatible with the hypothesis that the body forms dopa from tyrosine by ortho-oxidation at a slow rate and that it can deal only with small amounts of this oxidation product.

Another pathway of tyrosine metabolism is the introduction of iodine into the phenolic ring which occurs in the formation of di-iodotyrosine and thyroxine. When di-iodotyrosine is fed to rabbits, a large amount is excreted as 3:5-di-iodo-4-hydroxyphenyllactic acid, whilst some inorganic iodide is also found in the urine (Foster \& Gutman, 1930). It is most unlikely that any di-iodotyrosine is reduced again to tyrosine. This follows from the observations of Falta (1904) who fed 3:5-dibromotyrosine and iodinated casein to an alcaptonuric and found no change in the output of homogentisic acid. Abderhalden, Bloch \& Rona (1907) fed 3:5-di-iodotyrosine to an alcaptonuric without increase of the $H: \mathrm{N}$ ratio, but their result is not conclusive since the $2 \mathrm{~g}$. of the iodine compound fed could have caused only a statistically insignificant increase of homogentisic acid production. However, it is clear that the iodination of tyrosine represents a third, quantitatively limited, pathway of metabolism, not leading through the homogentisic acid stage.

Tyrosine may be catabolized by other mechanisms such as decarboxylation to tyramine; but it is very probable that both in man and other mammals paraoxidation is the major pathway and this is blocked completely in the alcaptonuric. In this sense the metabolic error in alcaptonuria is complete. The numerous observations which indicate that the $H: \mathrm{N}$ ratio drops if the nitrogen intake is reduced or if a ketogenic diet is given, may be explained by assuming that with a low nitrogen intake, alternate mechanisms become quantitatively more important. It is also possible that certain changes in the diet cause a greater diversion of tyrosine into pathways not involving homogentisic acid.

\section{The intermediate steps involved in the oxidation of tyrosine to homogentisic acid}

Currentideas on the exact chemical changes taking place in the conversion of tyrosine to homogentisic acid are mainly based on the work of Neubauer (1909) who found that both $p$-hydroxyphenylpyruvic and 2:5-dihydroxyphenylpyruvic acid increase homogentisic acid output in alcaptonuria. In an earlier paper (Neubauer \& Falta, 1904) it was shown that both $\beta$-phenyllactic and phenylpyruvic acid are converted to homogentisic acid by the alcaptonuric; with the keto acid the conversion was almost quantitative. It was assumed that tyrosine was first transformed to the keto acid which was then further oxidized in the para position to 2:5dihydroxyphenylpyruvic acid; this acid would then give homogentisic acid on decarboxylation. However, the evidence for this sequence of reactions is not conclusive. We know now that the oxidation of amino-acids to keto acids is a biologically reversible reaction and the apparent conversion of $p$-hydroxy phenylpyruvic acid to homogentisic acid might have occurred through tyrosine. Moreover, the increase in homogentisic acid excretion observed on feeding $p$-hydroxyphenylpyruvic acid was much lower than expected and Fromherz \& Hermanns (1914) with another alcaptonuric found only a conversion rate of $35 \%$.

Investigations have shown that 2:5-dihydroxyphenylalanine gives rise to increased excretion of homogentisic acid, presumably by being itself converted to that substance; but again this conversion is not quantitative. Both with tyrosine and phenylalanine the conversion appears quantitative only with the $l$-forms (Falta \& Langstein, 1903; Lanyar, 1942). It is probable that in our investigations some of the $d$-form was excreted in the urine, as shown by the reducing properties of the fraction from which homogentisic acid had been removed. It is difficult therefore to assess the quantitative significance of our findings. We can only conclude that an appreciable part, probably more than half, of the ingested $l$-form of dihydroxyphenylalanine has been converted to homogentisic acid. Thus it follows that oxidation of tyrosine to 2:5-dihydroxyphenylalanine followed by oxidative de-amination and decarboxylation represents at least one and possibly the most important pathway in the formation of homogentisic acid.

\section{Excretion of homogentisic acid}

Estimations of homogentisic acid in the plasma of the alcaptonuric have confirmed earlier observations that the concentration of this substance in the blood is extremely low, even after the giving of extra phenylalanine. In fact, the results are such that we cannot be quite sure that the reduction observed is due to homogentisic acid. There are two possible explanations for the low plasma and high urine concentrations and the consequently high apparent clearance volumes. It is possible that homogentisic acid is made mainly in the kidney and does not pass into the blood in significant amounts. The well-known fact that most alcaptonurics develop in later life ochronosis indicates that traces of homogentisic acid do escape into the general circulation, but the bulk may be directly secreted into the tubuli. The other possibility is that homogentisic acid is made in an organ other than the kidney, appears in the blood, but is actively secreted by the 
tubuli at a rate comparable to that shown by substances like di-iodone. Almost all substances so far known to have clearance volumes of a magnitude similar to that of renal blood flow are dyes and not intermediates in normal metabolism. The observation that a substance which arises in the metabolism of a normal dietary constituent should be secreted at a rate approaching that. of the renal blood flow would be of general interest.

A decision as to which of the two explanations is correct cannot be made on the basis of the facts so far available. The observations of Katsch \& Metz (1927) who administered homogentisic acid intravenously to an alcaptonuric without materially increasing the plasma concentration, would indicate that the material is excreted rapidly by the kidney from the blood. The amount given, however, was small and a repetition of such experiments with both normal people and alcaptonurics is very desirable, especially since it is not impossible that the abnormality of the alcaptonuric may consist of this high rate of renal secretion which removes homogentisic acid from the body before it can be further metabolized. If large differences between normal and alcaptonuric individuals in respect to renal clearance of homogentisic acid were indeed found, this would indicate that alcaptonuria is not due to the absence of an enzyme, but is caused by an abnormality in the secretory function of the kidney.

\section{The genetics of alcaptonuria}

The negative results obtained with the urines of both parents prove clearly that this case does not belong to the rare category of alcaptonuria which appears to be dominant. The fact that no traces of homogentisic acid could be found in the urines of the parents and other relatives, some of whom would be heterozygous with respect to the alcaptonuria gene, shows that this condition is truly recessive. The presence of a reducing substance resembling homogentisic acid in one of the urines tested is difficult to explain. This substance which appears to be a derivative of hydroquinone was found in several specimens of urine obtained from the subject and its concentration was greatly increased by ingestion of phenylalanine. It is likely, therefore, that the substance is formed during the metabolism of aromatic amino-acids, though the amount excreted corresponded only to a small fraction of the phenylalanine given. It is doubtful whether there is any connexion between the alcaptonuria in our patient and the excretion of this substance in this one relative, especially since the findings in the other members of the family were so completely negative.

\section{SUMMARY}

1. Chemical and other findings are reported in a case of alcaptonuria. It was shown that, apart from homogentisic acid, no other aromatic substances likely to arise in the intermediary metabolism of tyrosine and phenylalanine are excreted in abnormal and detectable quantities.

2. The variability of the daily excretion of homogentistic acid was investigated and it was found that even on a constant diet both the daily output of homogentistic acid and the $H: \mathrm{N}$ ratio vary considerably. It is pointed out that the extent of this variability has to be ascertained before any quantitative conclusions can be drawn from experiments in which the conversion of potential intermediates to homogentisic acid is investigated.

3. It was shown that phenylalanine and tyrosine are converted to homogentisic acid by the alcaptonuric to the extent of probably about $80-85 \%$. Catabolism by other pathways is discussed and it is concluded that, though these undoubtedly exist, they cannot account for more than $5-20 \%$ of the total aromatic amino-acids metabolized, at least under the conditions of ordinary mixed diet.

4. Neither the ingestion of ascorbic acid, nor of cysteine or methionine had any significant effect on the excretion of homogentisic acid. It was also shown that the alcaptonuric can deal with large doses of ascorbic acid in a normal manner.

5. Ingestion of $d l$-2:5-dihydroxyphenylalanine produced an increased excretion of homogentisic acid; it is suggested that tyrosine is normally first oxidized to 2:5-dihydroxyphenylalanine which is then converted to homogentisic acid through the keto acid.

6. The concentration of homogentisic acid in the plasma of the alcaptonuric was found to be very low, even after the giving of phenylalanine. The high renal clearance volumes found suggest that homogentisic acid is either formed in the kidney or actively excreted by the tubuli at a very high rate. The possibility that alcaptonuria may be due to an abnormality in the secretory function of the kidney is mentioned.

7. No trace of homogentisic acid was detected in the urines of other members of the family. One relative, however, excreted small amounts of a reducing substance which was not homogentisic acid, but which increased on ingestion of phenylalanine.

The authors wish to thank Prof. H. P. Himsworth for the clinical facilities, Dr C. E. Dent for carrying out the chromatographic experiments and Dr C. W. Emmens for help with statistical problems. 


\title{
REFERENCES
}

Abderhalden, E., Bloch, B. \& Rona, P. (1907). Hoppe-Seyl. Z. $52,435$.

Abderhalden, E. \& Falta, W. (1903). Hoppe-Seyl. Z. 39, 143.

Block, R. I. \& Bolling, D. (1945). The Amino-acid Composition of Proteins and Foods. Springfield, Ill.: Thomas.

Blum, L. (1908). Arch. exp. Path. Pharmak. 59, 269.

Braid, F. \& Hickmans, E. M. (1929). Arch. Dis. Childh. 4, 389.

Butts, J. S., Dunn, M. S. \& Hallman, L. F. (1938). J. biol. Chem. 123, 711.

Diaz, C. J., Mendoza, H. C. \& Rodriguez, J. S. (1939). Klin. $W s c h r .18,965$.

Embden, G. \& Baldes, K. (1913). Biochem. Z. 55, 301.

Embden, G., Salomon, H. \& Schmidt, F. (1906). Beitr. chem. Physiol. Path. 8, 129.

Falta, W. (1904). Dtsch. Arch. klin. Med. 81, 231.

Falta, W. \& Langstein, L. (1903). Hoppe-Seyl. Z. 37, 513.

Folin, O. \& Ciocalteu, V. (1927). J. biol. Chem. 73, 627.

Foster, G. L. \& Gutman, A. B. (1930). J. biol. Chem. 87, 289.

Fromherz, K. \& Hermanns, L. (1914). Hoppe-Seyl. Z. 91, 194.

Garrod, A. E. (1923). Inborn Errors of Metabolism, 2nd ed. London: Henry Froude \& Holder \& Houghton.

Glynn, L. E., Himsworth, H. P. \& Neüberger, A. (1945). Brit. J. exp. Path. 26, 326.

Guggenheim, M. (1913). Hoppe-Seyl. Z. 88, 276.

Hogben, L., Worrall, R. L. \& Zieve, I. (1932). Proc. Roy. Soc. Edinb., 52, part III, No. 13.

Katsch, G. (1918). Dtsch. Arch. klin. Med. 127, 210.

Katsch, G. (1920). Dtsch. Arch. klin. Med. 134, 59.

Katsch, G. \& Metz, E. (1927). Dtsch. Arch. klin. Med. 157, 143.

Langstein, L. \& Meyer, E. (1903). Dtsch. Arch. klin. Med. $78,161$.

Lanyar, F. (1942). Hoppe-Seyl. Z. 275, 217.

Lanyar, F. \& Lieb, H. (1931). Hoppe-Seyl. Z. 203, 135.

Leslie, A. (1943). Arch. intern. Med. 71, 68.
Levine, S. Z., Marples, E. \& Gordon, H. H. (1941). J. clin. Invest. 20, 199, 209.

Lieb, H. \& Lanyar, F. (1930). Hoppe-Seyl. Z. 186, 111.

Lorenz, E. (1937). Klin. Wschr. 16, 1463.

McCance, R. A. \& Widdowson, E. M. (1940). The Chemical Composition of Foods, Spec. Rep. Ser. Med. Res. Counc., Lond., no. 235.

Medes, G. (1932). Biochem. J. 26, 917.

Mittelbach, F. (1901). Dtsch. Arch. klin. Med. 71, 50.

Monsonyi, L. (1939). Pr. méd. 47, 708.

Moss, R. A. \& Schoenheimer, R. (1940). J. biol. Chem. 135,411 .

Neubauer, O. (1909). Dtsch. Arch. klin. Med. 95, 211.

Neubauer, O. (1928). Handb. norm. pathol. Physiol. 5, 851. Berlin: Julius Springer.

Neubauer, O. \& Falta, W. (1904). Hoppe-Seyl. Z. 42, 81.

Neuberger, A. (1947a). Biochem. J. 41, 431.

Neuberger, A. (1947b). To be published.

Neuberger, A. \& Webster, T. A. (1947). Biochem. J. 41, 449.

Papageorge, E. T., Fröhlich, M. M. \& Lewis, H. B. (1938). Proc. Soc. exp. Biol., N.Y., 38, 742.

Papageorge, E, T. \& Lewis, H. B. (1938). J. biol. Chem, 123, 211.

Penney, J. R. \& Zilva, S. S. (1945). Biochem. J. 39, 392.

Penrose, L. \& Quastel, J. H. (1937). Biochem. J. 31, 266.

Reinwein, H. (1931). Dtsch. Arch. klin. Med. 170, 327.

Roe, J. H. \& Kuether, C. A. (1943). J. biol. Chem. 147, 399.

Sachs, P. (1931). Dtsch. Arch. klin. Med. 170, 344.

Sealock, R. R., Galdston, M. \& Steele (1940). Proc. Soc. exp. Biol., N.Y., 44, 580.

Sealock, R. R., Perkinson, J. B. \& Basinski, D. H. (1941). J. biol. Chem. 140, 153.

Sealock, R. R. \& Silberstein, H. E. (1940). J. biol. Chem. $135,251$.

van Amstel, P. J. de Bruine (1910). Samml. klin: Vortr. 176-178, (562/64), 193.

Wolkow, E. \& Baumann, E. (1891). Hoppe-Seyl. Z. 15, 228.

\section{Studies on Alcaptonuria}

\section{EXPERIMENTAL ALCAPTONURIA IN RATS}

\author{
By A. NEUBERGER AND T. A. WEBSTER \\ The National Institute for Medical Research, London, N.W. 3
}

(Received 18 November 1946)

It was shown recently (Glynn, Himsworth \& Neuberger, 1945) that young albino rats reared on a diet devoid of both cystine and methionine excreted a urine which darkened on standing; incorporation of either of the two sulphur-containing amino-acids in the diet prevented the formation of this pigment or its precursor. The nature of the substance responsible

Biochem. 1947, 41 for the darkening of the urine yas not definitely established, but positive reactions for homogentisic acid were obtained. It was the primary purpose of the investigation reported in this paper to identify and isolate the substance and to determine the exact conditions which give rise to its excretion. 